iRASD Journal of Management
Volume 2, Number 2, 2020, Pages $100-108$
JRASD
https://journals.internationalrasd.org/index.php/jom

\title{
The Impacts of Tourism Risk Management, IT Adoption, Agility and Resilience on the Sustainable Tourism Supply Chain Performance of Maldives' Tourism Industry
}

Muhammad Azhar Bhatti ${ }^{1}$, Muhammad Atif Nawaz ${ }^{2}$

${ }^{1}$ Ph.D. Scholar, Department of Economics, The Islamia University of Bahawalpur, Pakistan, Email: azhar.bhatti219@gmail.com

${ }^{2}$ Department of Economics, The Islamia University of Bahawalpur, Pakistan, Email: atif.nawaz@iub.edu.pk

\begin{tabular}{|c|c|}
\hline \multicolumn{2}{|c|}{ ARTICLE INFO } \\
\hline \multicolumn{2}{|c|}{ Article History: } \\
\hline Received: & July 27,2020 \\
\hline Revised: & November 05, 2020 \\
\hline Accepted: & November 29, 2020 \\
\hline \multicolumn{2}{|c|}{ Available Online: December 31, 2020} \\
\hline \multicolumn{2}{|c|}{ Keywords: } \\
\hline \multicolumn{2}{|c|}{ Tourism IT adoption } \\
\hline \multicolumn{2}{|c|}{ Tourism risk management- } \\
\hline \multicolumn{2}{|c|}{ orientation } \\
\hline \multicolumn{2}{|c|}{ Tourism agility } \\
\hline \multicolumn{2}{|c|}{ Sustainable tourism } \\
\hline Supply cha & formance \\
\hline
\end{tabular}

ABSTRACT

Recently, the tourism industry has a significant role in economic growth worldwide and attain the attention of recent researchers. Therefore, the ongoing study aims to examine the role of tourism IT adoption, TR management orientation, and tourism agility on the sustainable tourism supply chain performance (STSCP) of Maldives' tourism industry. The investigation of mediating role of tourism supply chain resilience among the nexus of tourism IT adoption, TR management orientation, tourism agility, and sustainable tourism supply chain performance of Maldives' tourism industry are also included in the goal of the ongoing study. The data were obtained using questionnaires from the tourism industry employees related to the supply chain process, and AMOS has been utilized for analysis purposes. The results indicated that tourism IT adoption, TR management orientation, and tourism agility positively associate with the sustainable tourism supply chain performance of the Maldives' tourism industry. The findings also exposed that tourism supply chain resilience has played a positive mediating role among the nexus of tourism IT adoption, TR management orientation, tourism agility, and STSCP of the Maldives' tourism industry. These findings are guided to the policy developers and implementers that they should increase their focus on the tourism industry that could enhance the country's economic growth.

(c) 2020 The Authors, Published by iRASD. This is an Open Access article under the Creative Common Attribution Non-Commercial 4.0

Corresponding Author's Email: azhar.bhatti219@gmail.com

\section{Introduction}

Tourism is of great importance to many economies across the world (Nawaz \& Hassan, 2016b). The host destination economies enjoy several benefits of tourism. Tourism generates revenue for the host economy, creates many job opportunities, brings development in a country's infrastructure, and creates a cultural exchange between foreigners and citizens (Cuccia, Guccio, \& Rizzo, 2016). Considering the importance of tourism for a country, tourism supply chains are created, which binds the different entities involved in the tourism industry from the suppliers to the end consumers for the tourism industry's sustainable growth. Tourism supply chains have been catching the great attention of researchers, scholars, and practitioners. The better performance of the tourism supply chain determines the tourism industry's higher performance (Huang, 2018). The tourism supply chain consists of tourism suppliers, tour operators, travel agents, and customers, showing sustainable performance to attain higher growth of the tourism industry (Mandal, 2014). Several factors affect the performance of the tourism supply chain, some of which are addressed by this study, such as tourism IT adoption, the practices of TR management, and tourism agility (Lee \& Fernando, 2015). The adoption of information technology in the tourism industry provides the required information to the tourism supply chain management to perform their practices more effectively and efficiently. Also, the 
agility in the tourism activities makes relation among chain nodes stronger and determines sustainable tourism supply chain performance. Besides, the paper examines the mediating role of tourism supply chain resilience between tourism IT adoption, TR management, and tourism agility and STSCP.

Information technology plays an essential rule, even in driving our day-to-day operations. Particularly in any nature and any scope, information technology is widely used for performing different functions and deriving different operations. Tourism is one of the emerging economic industries (Nawaz \& Hassan, 2016a). Like the chain of other industries here in this tourism supply chain, the adoption of information technology has contributed a lot to the sustainable chain performance (Yuan, Tseng, \& Ho, 2019). In the Maldives, the tourism firms adopt information technology to plan, design, and offer the tour packages that may provide them with the competitive advantages aid the tourism supply chain to acquire, execute and transfer accurate, comprehensive, and reliable information across the chain.

TR management's function is to identify, evaluate, and prioritize the risks and coordinate and economically apply the resources to monitor the unfortunate events and minimize and control the negative impacts of those unfortunate events in the tourism firms. Furthermore, TR management also tries to create growth opportunities. The initiation of risk management in the firms within the tourism supply chain and TR management practices sustain the tourism supply chain performance (Williams \& Baláž, 2015). In the tourism industry within the supply chain, the risk may arise from the deficient collaboration of resources and procedures, which may put adverse effects on all the partner firms' performance within the chain, and it badly affects the performance of the tourism supply chain. In such a case, TR management identifies the risk and tries to remove it (Gligor \& Holcomb, 2012).

The agility in the tourism firms within the supply chain determines the sustainable supply chain performance. Agility in business is the organization's capability to rapidly respond to the changes in the business environment across the chain, in the quality of technology, in resources, in the quality of products provided by chain partners, and clients' preferences. Tourism agility makes the tourism firms in the supply chain since the changes and make their activities, services, and packages adaptive to these changes, which can meet the customer's demand adjusting to the marketplace changes and advantages to progress (Mandal \& Saravanan, 2019). The tourism firms investing in the tourism programs to earn foreign exchange revenue in the Maldives are contributing a lot to the sustainable tourism supply chain performance.

The study examines that tourism resilience is an appropriate mediator between tourism IT adoption, TR management, tourism agility, and STSCP (Tukamuhabwa, Stevenson, Busby, \& Zorzini, 2015). Tourism resilience is the capability of tourism firms to recover quickly from the business's disturbance, adversities, risks, threats, relationship problems, and serious issues. The tourism IT adoption, TR management, and tourism agility aids supply chain resilience, which further proves to be beneficial for the attainment of sustainable supply chain management.

\section{Literature Review}

Tourism is the short-term temporary movement of people to a destination outside the place where they normally live or work and their activities at the time of their visit and stay at outside destinations. In the Maldives, tourism has become the largest economic industry as it has become the most significant source of generating foreign exchange revenues and creating employment opportunities in the third rank sector of the economy. The archipelago of the Maldives is the primary source of attraction to the tourists visiting the island country. In the Maldives, the tourism industry was started in 1972. With time, the tourism industry in the Maldives has been growing. Tourism in the Maldives started with two resorts having a capacity of just 280 beds. Kurumba Island Resort was the first island resort launched in the Maldives, followed by Bandos Island Resort. By now, more than 132 resorts are located in the atolls of the Maldives, providing tour services and generating foreign exchange revenue. There are many thanks to the alteration in regulation that allowed the tourist to remain among the general population of Maldives. In the Maldives, the tourism supply chain plays a vital role in the growth of the tourism industry. The sustainable performance of the tourism supply chain contributes a lot to the tourism industry's performance and growth and the economic growth of Maldives by 
generating foreign exchange revenue and generating employment opportunities for the local population.

On the other hand, tourism IT adoption, TR management, and tourism agility are some of the primary sources of STSCP. Tourism information technology provides the required information to the supply chain management to configure and integrate different procedures and resources to meet tourists' up-to-date requirements. Likewise, the TR management helps the host destination management control the chances of the risks and threats and their adverse effects and thereby attain the sustainable tourism supply chain performance (Clinch \& Filimonau, 2017). Moreover, the agility in the activities of tourism improves the speed and accuracy of supply chain management and improves its performance.

According to Pesonen, Komppula, and Riihinen (2015), tourism information technology adoption is the ability of tourism firms to acquire and utilize information technology to properly plan for and promote tourism services, tourism resources, and tourism packages. Such ability helps supply chain partner firms plan their tourism services and packages appropriately using up-to-date information technology. In the emerging competitive market atmosphere in the service industry, the organizations within the tourism supply chain can design, plan, and present competitive packages that are likely to attain customer's trust and superior market share. Thus, information technology benefits may be attained only when the partner tourism firms within the supply chain can adapt and adapt to innovative information technology and the ability to utilize the information technology to design their services and packages (Raman \& Bharadwaj, 2017). Moreover, such a capability to adopt information technology in the tourism industry also improves the tourism supply chain's performance as it helps it utilize information technology for business uncertainty and planning to present sustained services to the tourist (Xiang, 2018). In the Maldives, the tourism industry's supply chain shows sustainable performance due to the adoption and adaption of up-to-date information technology and deploying them to offer competitive tourism packages.

H1: Tourism IT adoption has a positive association with sustainable supply chain performance.

The tourism supply chain must show sustainable performance even in all circumstances, which is difficult in risks and threats. In the chains of all the financial industries, uncertainties and contingencies are there, which may result in risks or opportunities (Wagner \& Bode, 2008). In both cases, the risk management should perform their functions actively, they should keep an eye on the chances of risks to overcome them at the right time, and they should also predict the opportunities of progress to benefit from them at the right time (Mikulić, Sprčić, Holiček, \& Prebežac, 2018). Similarly, in the tourism supply chain, risks may arise from several sources like circulating information across the chain, acquisition of knowledge about the quality of raw material, deficient collaboration of procedures or resources, leakage of private information of the tourism firms, and bad relationships (Swafford, Ghosh, \& Murthy, 2008). These risks may result in many forms like risk reduction, team member productivity, cost-effectiveness, and the reduction of profitability as lack of quality and reputation. The TR management keeps monitoring the chances of risks, it tries to eliminate these unfortunate chances before the occurrence, and it minimizes or removes the adverse effects of the unfortunate events that attain the sustainable tourism supply chain performance. Similarly, TR management keeps an eye on the fortunate events so that they may benefit from opportunities (Liu, Cheng, \& OuYang, 2019). The Maldivian tourism industry has been emerging rapidly and has become the world's second-largest tourism industry as TR management brings sustainable supply chain performance.

\section{H2: TR management has a link with sustainable supply chain performance.}

Sustainability in the tourism supply chain performance is likely to be achieved in agility in the tourism supply chain nodes. A long-term investigation has proved that the supply chain's sustainable performance depends on the right information and knowledge circulating across the supply chain. The complete, adequate, and reliable information and accurate knowledge and awareness is acquired, stored, execute, and transfer within the tourism firms in the chain, which is adaptive to the changes in marketplaces, business environment, tourists demands and nature of tourism packages, the tourism supply chain show sustainable performance (Sudapet, Sukoco, 
\& Setiawan, 2019). On the contrary, if the individual tourism firms within the chain do not keep pace with the changes and do not keep their activities, services, tourism packages, and tourism products as per the changing tourists' requirements, it not only adversely affects its performance but also affects the performance of supply chain. With the lack of agility capability, the individual firms themselves become paralyzed when it has to face the changes in the market, customers' requirements and environment (Xu \& Gursoy, 2015). They paralyze the other partner firms within the chain by sharing information that is not up-date, thereby adversely affecting the supply chain performance (Mandal, Roy, \& Raju, 2016). Thus,

H3: Tourism agility imparts positive influences on tourism supply chain management.

The resilience in Individual firms in the chain brings improvement in their performance and the performance of the supply chain from the procurement of material to the end consumption of finished products. Similarly, the tourism firms having the resilience quickly adapt to the disruption while maintaining current operations and safeguarding physical, financial, and brand equity, which aids sustainable supply chain performance. The tourism IT adoption contributes to the tourism supply chain resilience as the adoption and use of up-to-date information technology provides quick, accurate, abundant, reliable, and most crucial innovative information which is circulated in the supply chain and help the supply chain to recover from risks, disasters, and losses which further aids the supply chain to attain the sustainable performance (Li, Hu, Huang, \& Duan, 2017). Likewise, TR management identifies the chances of risks and threats and the progressive opportunities which help the supply chain in recovering from the risks, threats, disasters, and adverse effects of unfortunate events (Navío-Marco, RuizGómez, \& Sevilla-Sevilla, 2018). Besides, the agility in the tourism firm creates supply chain resilience as if the individual firms can sense the changes in the market and business environment, and in the tourist's demands and to make a quick response to these changes being adaptive help the supply chain recover from the losses, disasters, and risks as soon as possible and the supply chain resilience created in this way makes the supply chain performance sustainable (Buhalis \& Sinarta, 2019).

H4: Supply chain resilience is an essential mediator between tourism IT adoption and sustainable tourism supply chain performance.

H5: Supply chain resilience plays a mediating role between TR management and sustainable supply chain performance.

H6: Supply chain resilience is a considerable mediator between tourism agility and sustainable supply chain performance.

\section{Research Methods}

The current study aim is to examine the role of tourism IT adoption, TR management orientation, and tourism agility on the STSCP along with the investigation of mediating role of tourism supply chain resilience among the nexus of tourism IT adoption, TR management orientation, tourism agility and STSCP of Maldives' tourism industry. The study has executed the primary data collection methods, and simple random sampling was used to select the respondents. The data were obtained using questionnaires from the tourism industry employees that are related to the supply chain process. A total of 490 questionnaires were sent to the respondents by personal visit along with the mail. After fifteen days, 290 questionnaires were returned, which has a 59.18 percent response rate. In addition, AMOS has been utilized for analysis purposes because the purpose of the study is hypothesis testing. The variables that are used by the ongoing study include one predictive variable named STSCP that has five items (Mandal, 2018). In addition, the present study takes only one mediator named tourism supply chain resilience (TSCR) that has four items (Mandal \& Saravanan, 2019). Finally, the present study adopted three predictors named tourism IT adoption (TITA) that has four items (Oliveira \& Martins, 2010), TR management orientation (TRMO) that also has four items (Becken \& Hughey, 2013), and tourism agility (TA) that also has four items (Roy, Amar, \& Mandal, 2016). The variables, along with items, have been mentioned in Figure 1. 


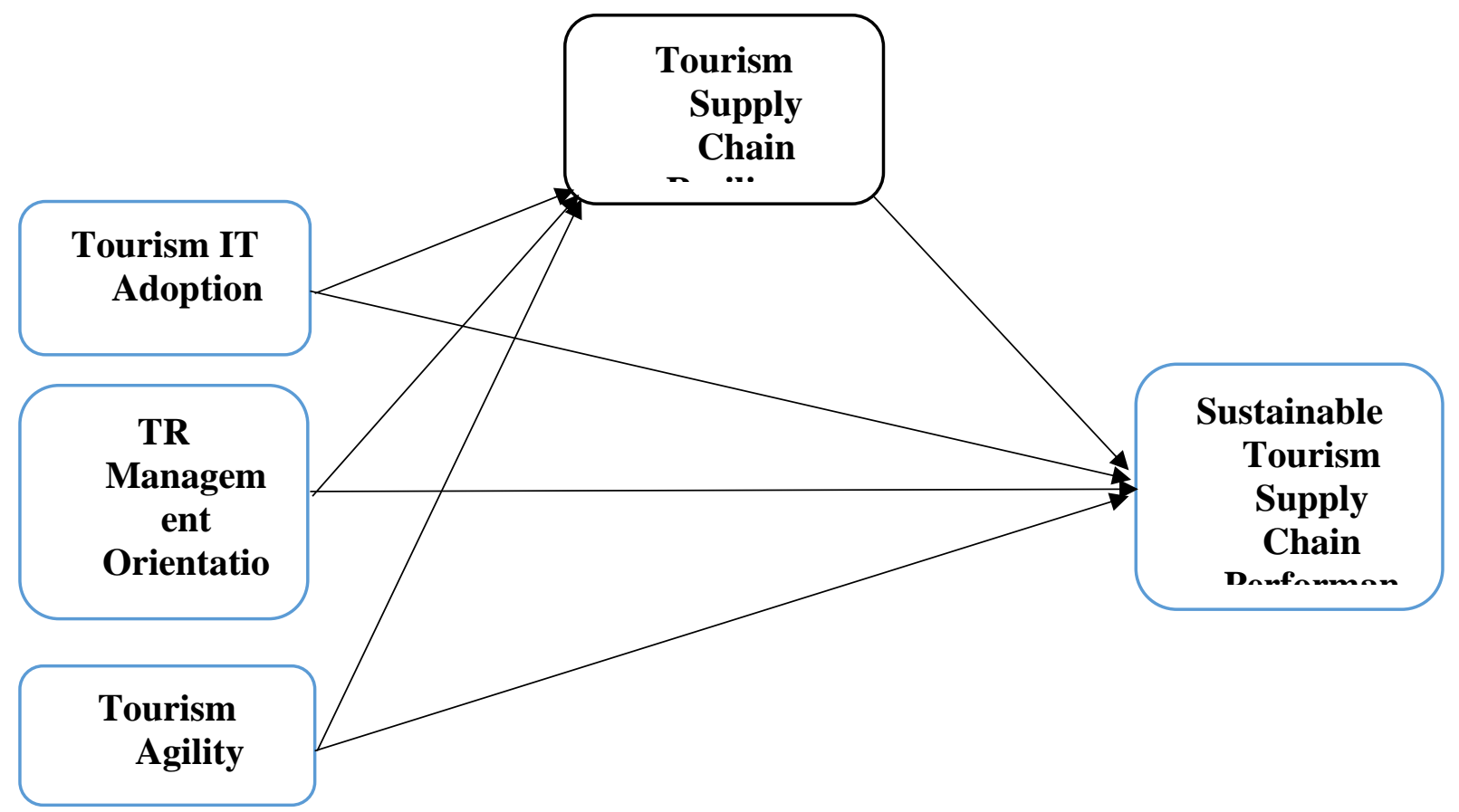

Figure 1: Theoretical model

\section{Results}

The present study results consist of the assessment of the measurement model, along with the assessment of the structural model. The measurement model assessment includes the checking of validity and reliability of the items and constructs through convergent and discriminant validity. Besides, assessment of the structural model includes the testing of hypotheses through path analysis. Firstly, the measurement model's assessment has been executed, and Table 1 shows the convergent validity where loadings and AVE are more than 0.50 while CR values are more extensive than 0.70 . These are the indications of high correlation among items along with valid convergent validity.

\section{Table 1}

\section{Convergent validity}

\begin{tabular}{llccc}
\hline Constructs & Items & Loadings & CR & AVE \\
\hline Tourism IT Adoption & AITA4 & 0.998 & 0.953 & 0.840 \\
& AITA3 & 0.836 & & \\
& AITA2 & 0.821 & & \\
TRM Management Orientation & AITA1 & 0.997 & & 0.841 \\
& TRMO4 & 0.992 & 0.954 & \\
& TRMO3 & 0.640 & & \\
Tourism Agility Sustainable & TRMO2 & 0.995 & & \\
& TRMO1 & 0.740 & & \\
& TA4 & 0.876 & 0.914 & \\
& TA3 & 0.849 & & \\
Tourism Supply Chain Resilience & TA2 & 0.828 & & \\
& TA1 & 0.826 & & \\
& TSCR4 & 0.989 & 0.909 & 0.714 \\
& TSCR3 & 0.994 & & \\
Tourism Supply Chain Performance & TSCR2 & 0.627 & & \\
& TSCR1 & 1.000 & & \\
& STSCP5 & 0.719 & 0.890 & 0.620 \\
& STSCP4 & 0.850 & & \\
& STSCP3 & 0.787 & & \\
\hline
\end{tabular}

The measurement model's assessment has also included the checking of discriminant validity that has been highlighted in Table 2, where the values that show links with the variable 
itself are larger than the values that show the links with other constructs. These are the indications of low correlation among variables along with valid discriminant validity.

Table 2

Discriminant validity

\begin{tabular}{llllll}
\hline & TSCR & AITA & TRMO & TA & STSCP \\
\hline TSCR & 0.916 & & & & \\
AITA & 0.443 & 0.917 & & & \\
TRMO & 0.688 & 0.427 & 0.856 & & \\
TA & 0.334 & 0.361 & 0.364 & 0.845 & 0.788 \\
STSCP & 0.454 & 0.406 & 0.453 & 0.399 & 0.78 \\
\hline
\end{tabular}

The results also show the model fit that is the analysis of the model that would fit the analysis, and the figures show that the model is fit for analysis because the CFI and GFI values are higher than 0.90 . Moreover, the AGFI, NFI values are more than 0.80 . In addition, CMIN/DF values are between 1 to 5; however, RMR and RNSEA values are lower than 0.80 while PGFI value is higher than 0.50 that are the pieces of evidence of model fit. These values are mentioned in Table 3.

\section{Table 3}

\section{Model Fit}

\begin{tabular}{lccc}
\hline Fit Index & Admissibility & Result & Fit (Yes/No) \\
\hline CMIN/DF & $1.00-5.00$ & 4.106 & Yes \\
CFI & $>0.90$ & 0.947 & Yes \\
GFI & $>0.90$ & 0.925 & Yes \\
AGFI & $>0.80$ & 0.874 & Yes \\
PGFI & $>0.50$ & 0.541 & Yes \\
RMR & $<0.80$ & 0.414 & Yes \\
NFI & $>0.80$ & 0.855 & Yes \\
RMSEA & $<0.80$ & 0.274 & Yes \\
\hline
\end{tabular}

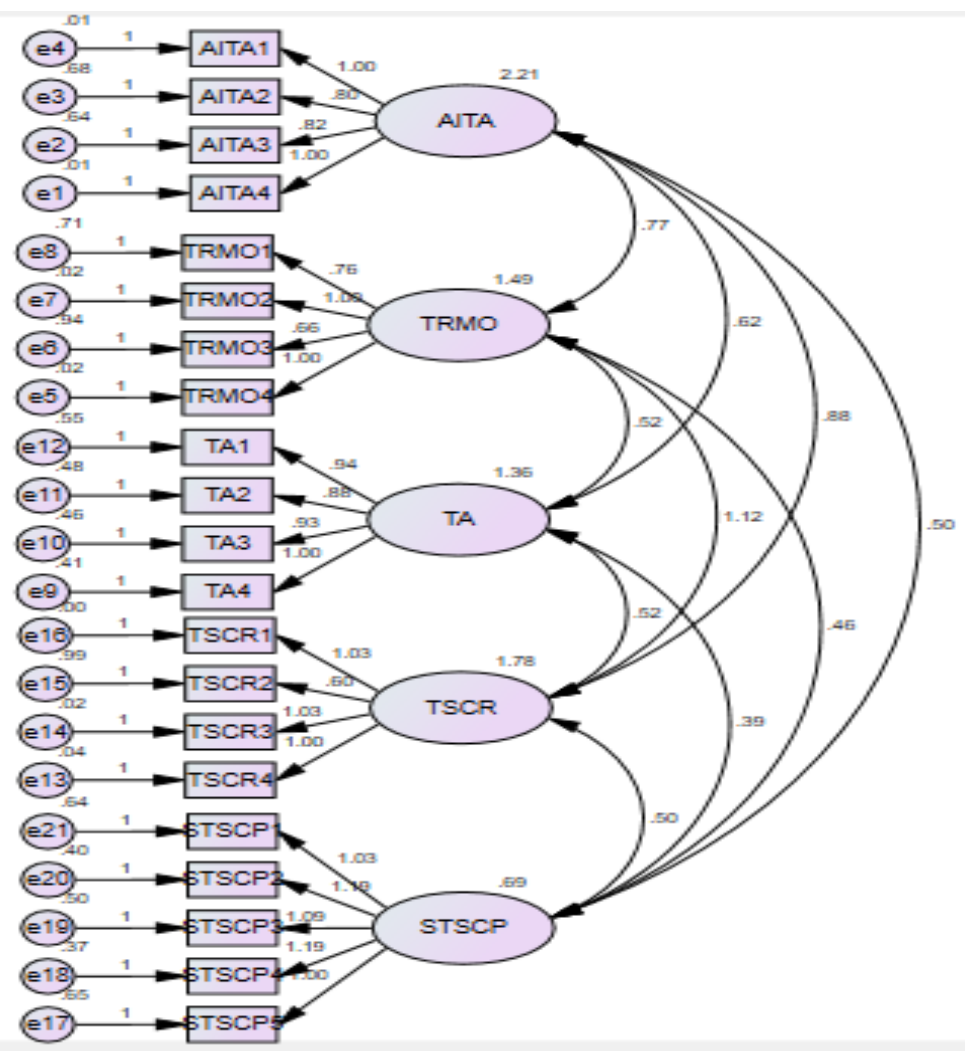

Figure 2: Measurement model assessment

Finally, the structural model assessment has been made, and the path analysis shows that tourism IT adoption, TR management orientation, and tourism agility have a positive 
association with STSCP of Maldives' tourism industry and accept $\mathrm{H} 1, \mathrm{H} 2$, and $\mathrm{H} 3$. The findings also exposed that tourism supply chain resilience has played a positive mediating role among the nexus of tourism IT adoption, TR management orientation, and tourism agility, and STSCP of Maldives' tourism industry and accept H4, H5, and H6. These values are shown in Table 4.

\section{Table 4}

\section{A path analysis}

\begin{tabular}{lcccc}
\hline Relationships & Beta & S.D. & t-statistics & p-values \\
\hline TRMO - > STSCP & 0.123 & 0.048 & 2.563 & 0.010 \\
TA -> STSCP & 0.148 & 0.041 & 3.629 & 0.000 \\
AITA -> STSCP & 0.100 & 0.031 & 3.239 & 0.001 \\
TSCR -> STSCP & 0.117 & 0.047 & 2.477 & 0.013 \\
TRMO -> TSCR -> STSCP & 0.214 & 0.051 & 4.196 & 0.005 \\
TA -> TSCR -> STSCP & 0.174 & 0.038 & 4.579 & 0.004 \\
AITA -> TSCR -> STSCP & 0.382 & 0.061 & 6.262 & 0.001 \\
\hline
\end{tabular}

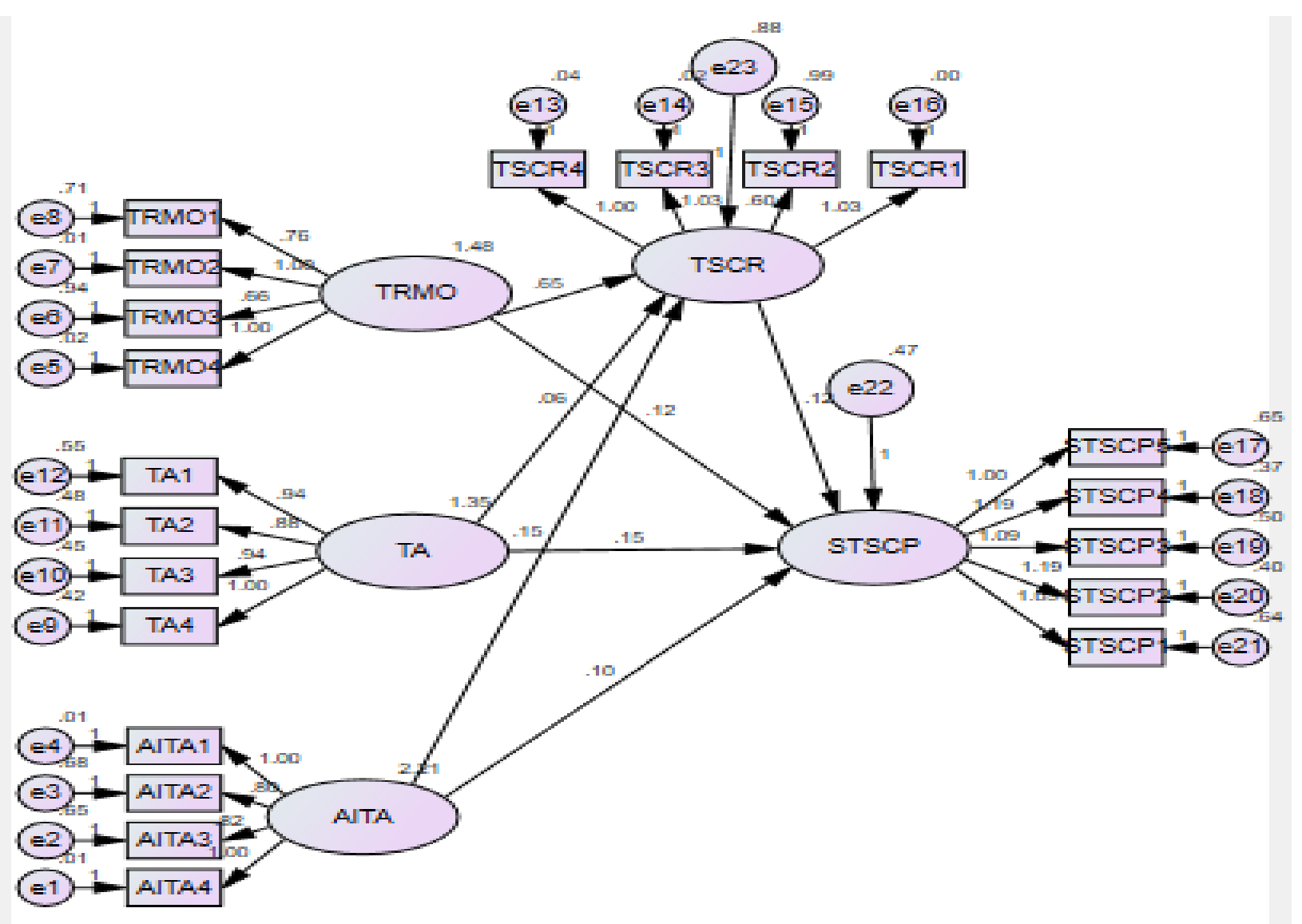

Figure 3: Structural model assessment

\subsection{Discussion and Implication}

The results have revealed that tourism IT adoption has a positive relationship with sustainable supply chain performance. These results are in line with the previous studies of Xiang, Magnini, and Fesenmaier (2015), which indicate the crucial role of tourism IT adoption in the sustainable supply chain performance. These results have indicated that TR management has positive influences on sustainable supply chain performance. These results agree with the past studies of Franzoni and Pelizzari (2016), where there is a focus on implementing the practices of TR management for attaining sustainable supply chain performance. Moreover, the results have revealed that tourism agility has positive effects on sustainable supply chain performance. These results match with Amar Raju, Roy, and Mandal (2018) studies according to which tourism agility is a significant driver of sustainable supply chain performance. The results have revealed that the tourism supply chain resilience is a mediator between tourism IT 
adoption and sustainable supply chain performance. These results match with the previous studies of Hosseini, Ivanov, and Dolgui (2019), which has shown that tourism IT adoption adds to the supply chain resilience, which further brings sustainable supply chain performance. The results have also proved that tourism resilience plays a mediating role between TR management and sustainable supply chain performance. These results are in accordance with the results of past studies Hosseini et al. (2019).

The study contributes to the literature on tourism management as it throws light on the three drivers of sustainable tourism supply chain performance, such as tourism IT adoption, TR management, and tourism agility. The supply chain resilience is an appropriate mediator between tourism IT adoption, TR management, tourism agility, and sustainable tourism supply chain performance. Besides the theoretical implication, this paper also carries empirical implication as it proves to be of great importance to tourism management and provides it with the guideline of how to attain sustainable tourism supply chain performance with tourism IT adoption, implementation of the practices of TR management, and attainment of tourism agility.

\section{Conclusion and Limitation}

In conclusion, it can be said that there is a positive association between tourism IT adoption and sustainable tourism supply chain performance. The study has approved that the implementation of TR management efficient practices results in the achievement of sustainable tourism supply chain performance. Also, the paper examines the positive effects of tourism agility in the sustainable tourism supply chain performance. The results have also revealed that tourism supply chain resilience is a mediator between sustainable tourism supply chain performances.

The study has shed light on the three contributors to sustainable tourism supply chain performance like tourism IT adoption, TR management, and tourism agility, despite all it has some limitations. It explores only three contributors to sustainable tourism supply chain performance while many other factors affect the sustainable tourism supply chain performance that must be explored by future scholars. Moreover, only a single source of data collection has been used here, and future scholars should use more than one source of data collection. Here in this paper, tourism resilience has been used as a mediator between tourism IT adoption, TR management, tourism agility, and STSCP. In contrast, the same variable should be used as a moderator by future academics.

\section{References}

Becken, S., \& Hughey, K. F. (2013). Linking tourism into emergency management structures to enhance disaster risk reduction. Tourism Management, 36, 77-85.

Buhalis, D., \& Sinarta, Y. (2019). Real-time co-creation and nowness service: lessons from tourism and hospitality. Journal of Travel \& Tourism Marketing, 36(5), 563-582.

Clinch, H., \& Filimonau, V. (2017). Instructors' perspectives on risk management within adventure tourism. Tourism Planning \& Development, 14(2), 220-239.

Cuccia, T., Guccio, C., \& Rizzo, I. (2016). The effects of UNESCO World Heritage List inscription on tourism destinations performance in Italian regions. Economic Modelling, 53, 494-508.

Franzoni, S., \& Pelizzari, C. (2016). Weather risk management in tourism industry. Symphonya. Emerging Issues in Management(1), 45-55.

Gligor, D. M., \& Holcomb, M. C. (2012). Antecedents and consequences of supply chain agility: establishing the link to firm performance. Journal of Business Logistics, 33(4), 295-308.

Hosseini, S., Ivanov, D., \& Dolgui, A. (2019). Review of quantitative methods for supply chain resilience analysis. Transportation Research Part E: Logistics and Transportation Review, 125, 285-307.

Huang, C.-w. (2018). Assessing the performance of tourism supply chains by using the hybrid network data envelopment analysis model. Tourism Management, 65, 303-316.

Lee, H. K., \& Fernando, Y. (2015). The antecedents and outcomes of the medical tourism supply chain. Tourism Management, 46, 148-157.

Li, Y., Hu, C., Huang, C., \& Duan, L. (2017). The concept of smart tourism in the context of tourism information services. Tourism Management, 58, 293-300. 
Liu, Y., Cheng, P., \& OuYang, Z. (2019). Disaster risk, risk management, and tourism competitiveness: A cross-nation analysis. International Journal of Tourism Research, 21(6), 855-867.

Mandal, S. (2014). Supply chain resilience: a state-of-the-art review and research directions. International Journal of Disaster Resilience in the Built Environment, 5(4), 427-453.

Mandal, S. (2018). Exploring the influence of big data analytics management capabilities on sustainable tourism supply chain performance: the moderating role of technology orientation. Journal of Travel \& Tourism Marketing, 35(8), 1104-1118.

Mandal, S., Roy, S., \& Raju, G. A. (2016). Tourism supply chain agility: an empirical examination using resource-based view. International Journal of Business Forecasting and Marketing Intelligence, 2(2), 151-173.

Mandal, S., \& Saravanan, D. (2019). Exploring the influence of strategic orientations on tourism supply chain agility and resilience: An empirical investigation. Tourism Planning \& Development, 16(6), 612-636.

Mikulić, J., Sprčić, D. M., Holiček, H., \& Prebežac, D. (2018). Strategic crisis management in tourism: An application of integrated risk management principles to the Croatian tourism industry. Journal of destination marketing \& management, 7, 36-38.

Navío-Marco, J., Ruiz-Gómez, L. M., \& Sevilla-Sevilla, C. (2018). Progress in information technology and tourism management: 30 years on and 20 years after the internetRevisiting Buhalis \& Law's landmark study about eTourism. Tourism Management, 69, 460-470.

Nawaz, M. A., \& Hassan, S. (2016a). Investment and Tourism: Insights from the literature. Journal of Economic \& Management Perspectives, 10(4), 581-590.

Nawaz, M. A., \& Hassan, S. (2016b). Tourism in South Asia. International Journal of Economic Perspectives, 10(4), 591-601.

Oliveira, T., \& Martins, M. F. (2010). Information technology adoption models at firm level: review of literature. Paper presented at the The European Conference on Information Systems Management.

Pesonen, J., Komppula, R., \& Riihinen, A. (2015). Typology of senior travellers as users of tourism information technology. Information Technology \& Tourism, 15(3), 233-252.

Raman, A., \& Bharadwaj, S. S. (2017). Dynamic service capabilities enabling agile services. Journal of Enterprise Information Management, 30(1), 166-187.

Roy, S., Amar, R. G., \& Mandal, S. (2016). A dynamic capability view on tourism supply chain resilience: Evidence from Indian tourism sector. Journal of Environmental Management \& Tourism, 7(13), 133-138.

Sudapet, I. N., Sukoco, A., \& Setiawan, M. I. (2019). Influence of Supply Chain Integration, IT Practices and Visibility on Modular Design and Supply Chain Agility, Supported Maritime and Tourism Business in Indonesia. Int. J Sup. Chain. Mgt Vol, 8(6), 420-434.

Swafford, P. M., Ghosh, S., \& Murthy, N. (2008). Achieving supply chain agility through IT integration and flexibility. International journal of production economics, 116(2), 288297.

Tukamuhabwa, B. R., Stevenson, M., Busby, J., \& Zorzini, M. (2015). Supply chain resilience: definition, review and theoretical foundations for further study. International Journal of Production Research, 53(18), 5592-5623.

Wagner, S. M., \& Bode, C. (2008). An empirical examination of supply chain performance along several dimensions of risk. Journal of Business Logistics, 29(1), 307-325.

Williams, A. M., \& Baláž, V. (2015). Tourism risk and uncertainty: Theoretical reflections. Journal of Travel Research, 54(3), 271-287.

Xiang, Z. (2018). From digitization to the age of acceleration: On information technology and tourism. Tourism management perspectives, 25, 147-150.

Xiang, Z., Magnini, V. P., \& Fesenmaier, D. R. (2015). Information technology and consumer behavior in travel and tourism: Insights from travel planning using the internet. Journal of retailing and consumer services, 22, 244-249.

$\mathrm{Xu}, \mathrm{X} .$, \& Gursoy, D. (2015). Influence of sustainable hospitality supply chain management on customers' attitudes and behaviors. International journal of hospitality management, 49, 105-116.

Yuan, Y., Tseng, Y.-H., \& Ho, C.-I. (2019). Tourism information technology research trends: 1990-2016. Tourism review, 74(1), 5-19. 